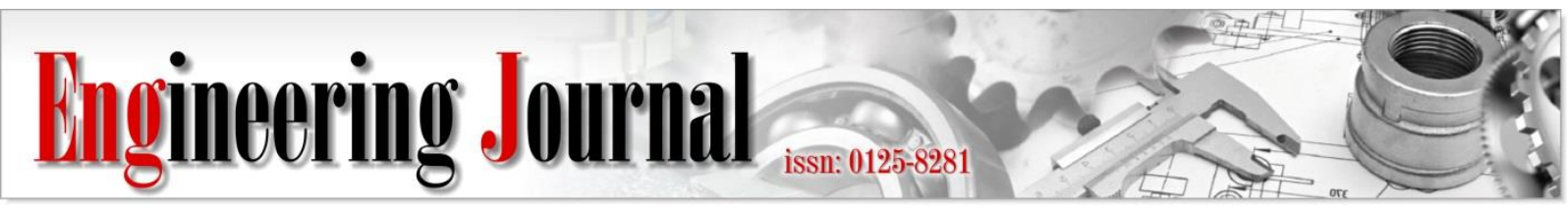

Article

\title{
A Dynamic Model for Simulating Elephant-Lifting by Using a Tilting Frame
}

\author{
Komsam Mianpet ${ }^{\mathrm{a},{ }^{*}}$ and Satjarthip Thusneyapan ${ }^{\mathrm{b}}$ \\ Department of Mechanical Engineering, Faculty of Engineering, Kasetsart University, Bangkok 10900, \\ Thailand \\ E-mail: amianpet.ks@hotmail.com (Corresponding author), bfengsit@ku.ac.th
}

\begin{abstract}
A rigid multi-body dynamic model of an elephant was developed for motion analysis during tilt-lifting. The elephant lifting to standing position is required by veterinarians to perform surgery and bedsores treatment. The elephant mechanism dynamic model (EMDM) was developed by simplifying the skeleton to simple straight linkages connected by joints. The model consisted of 10 bones and 9 joints. A mechanical harness model (MHM) was developed. Two harnesses were attached to the tilt-frame mechanism model (FMM) and the EMDM; this assembly became the elephant dynamic during tilt-lifting model (EDTM). The developed EDTM permitted us to observe the displacement, velocity, and acceleration responses at any location on the elephant. The model allowed the virtual study of the motion, and avoided the real elephant testing; thus, the cost, time, and resources were reduced and no conflict with the animal experimental ethics. The simulation was found to be a valuable tool for engineers to design a suitable elephant bed. It permitted us to observe the operation, safety, and precaution of the equipment.
\end{abstract}

Keywords: Multi-body dynamic, elephant, joint, tilt-lifting, biomechanism.

ENGINEERING JOURNAL Volume 24 Issue 5

Received 5 November 2019

Accepted 3 August 2020

Published 30 September 2020

Online at https:/ / engj.org/

DOI:10.4186/ej.2020.24.5.195 


\section{Introduction}

The use of computers to study human motion, by using an assembly model of human parts with movable limbs and joints, were applied for ergonomic analysis in the production line [1]. This paper demonstrates the benefits of ergonomics for production line planning. However, for a better planning result, the human body features must suit Asian people. The ergonomics analysis and simulation were applied for improving the efficiency of assembly work postures [2]. This study used a software simulation for simulating body postures and investigating the causes of musculoskeletal disorder. They proposed a work posture improvement to reduce worker fatigue. Topics of kinematic of athletes' motion are research topics in sports science and engineering that are reported by Subic and Haake [3]. The fundamental theory and application of mechanism controlling locomotion and manipulation systems for humanoid and worm robots are a subject for undergraduate and graduate studies as presents by Zimmermann, et al., [4].

The knee-hip joint control of a quadruped robot to achieve smooth gaits by using a control algorithm was developed by Wang, et al., [5]. Modeling of muscle by using shape memory alloy of a quadruped robot model is introduced by Öztürk, et al., [6]. They used computeraided engineering to analyze the dynamic characteristic of the system. The use of pneumatic artificial muscles as actuators for the limb movements of quadruped robots, with the design objective for the motion of high frequency up to $7.5 \mathrm{~Hz}$, was performed by Narioka, et al., [7]. They successfully developed a robot as a platform for fast locomotion studies.

Aspects of legged locomotion find in insects and vertebrates provide improvement for the design and control of legged robots [8]. They found locomotion similarities in insects and legged animals.

The fish movement imitation of fish robots for the acceptance by live fishes was developed by Landgraf, et al., [9]. This biomimetic robot is used in the natural environment without disturbing the live fishes; so that the natural movement patterns of live fishes can be examined.

The investigations of the structural and functional of animal joints, for the purposed of apply engineering mechanics and joints to the biological skeleton, were investigated by Mow and Lai [10]. Hutchinson, et al., analyzed the locomotor kinetics from 14 African and 48 Asian elephants ranging from 116 to $4632 \mathrm{~kg}$ and moving from 0.4 to $6.8 \mathrm{~m} / \mathrm{s}$ [11]. They found the elephants move similar to many quadrupeds. Their study indicates some differences between the two species in size-independent kinetic parameters. Their kinetic data of locomotor patterns have potential use for indicating the elephants' musculoskeletal disorders.

The body size affects the motion of the elephants' center-of-mass (COM) was studied by Genin, et al., [12]. From 34 Asian elephants during the speed from 0.4 to 5.0 $\mathrm{m} / \mathrm{s}$, they found the work per unit-distance to maintain the movement of the COM is around $0.2 \mathrm{~J} /(\mathrm{kg} \cdot \mathrm{m})$. At high speed, the vertical oscillation of the COM is $1 \mathrm{~cm}$ comparing to $3 \mathrm{~cm}$ at low speed.

The locomotion of elephant walking and running were video recorded for gait analysis by Ren, et al., [13]. They measured flexion-extension of limb-and-joint angles and its angular velocities. The data, of 7 African and 8 Asia elephants, indicates $31 \%$ to $77 \%$ of their joint rangeof-motion is used during rapid locomotion. These results are the same for both African and Asian elephants.

Maes and Abourachid measured the footfall patterns of dogs and studied the interlimb coordination pattern, such as walk, run, and gallop [14]. The study reported the coordination is controlled during the swing phase; and, mechanics drive the stance phase.

The length, mass, and circumference of limb bones of elephants were studied by Fuller [15]. This research shows the measurements of bone circumference and length give an acceptable approximation of the body mass.

The elephant is the national animal of Thailand, they are found in all regions in the country. Thai elephant specie is Elephas maximus indicus, a sup-specie of Asia elephants $[16,17]$. The causes of elephant injuries are from road accidents, mine-explosion, ivory cut, and people attack. When an injured elephant collapsed, it could not stand by its muscle power. The prolonged sidelaying position causes bedsores, which is more fatal than its illness. To treat bedsores, veterinarians recommend changing the position from one side to the other every two hours, thus a special elephant bed is a need for lifting the elephant to standing position and allow it to lay down to the other side.

Animal testing and experiment are under ethical considerations [18]. Before performing experiments on animals, the research procedure must be reviewed by animal ethics committees.

The acceleration of human motion was one of the parameters used to indicate the risk of injury as concerned in ISO 2631 [19]. This ISO 2631 described methods of quantifying whole-body vibration to human comfort and health. Human perception of motion during earthquakes in high-rise buildings is the psychological effects of fear and anxiety [20]. Similar to the human perception of motion, it can be found in animals. The variations of displacement, velocity, and acceleration during the unnatural motion by human-made equipment introduced elephants uncomfortable and frightening. This effect would increase the difficulty in lifting, transportation, and saving elephants.

The crane-and-hoist system is a conventional method of helping an elephant to its feet as illustrates in Fig. 1(a). This figure shows an adult elephant body is wrapped around by two harnesses, each for one lifting crane; one harness is placed around the chest at forelimbs, the other around the hip at hind-limbs. For a small elephant, as in Fig. 1(b), one harness-and-crane is used.

Our simulation was performed using the elephant bed in the thesis presented by Chamsa [21]. His bed structural 
a)

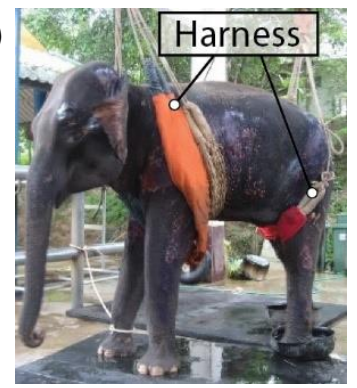

c)

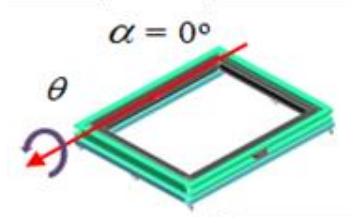

e)

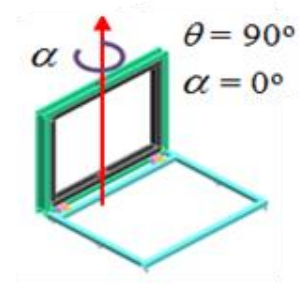

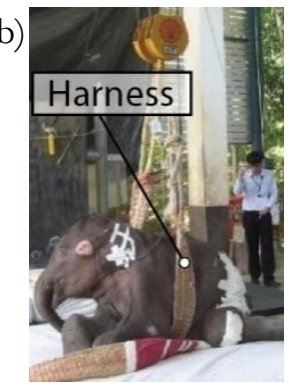

d) $\theta=45^{\circ}$

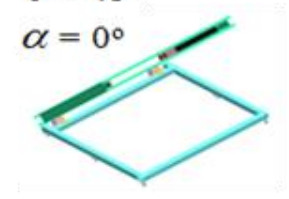

f)

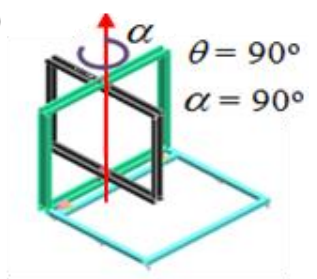

Fig. 1. Elephant lifting by using harnesses and cranes: a) adult elephant, b) elephant calf, and c) to f) the operation sequences of the bedsore-bed designed by Chamsa.

design based on the $5000 \mathrm{~kg}$ elephant with the size was within an envelope of L4500, H3500 and W1500 mm. The bed design intention was for treating bedsores; where the elephant needs to lift to the upright position and laying it down to the opposite side. His bed accommodated the bedsores treatment and surgery; the concept of the operation is shown in Fig. 1(c) to (f). The elephant lifting is possible by rotate $\theta$-angle, of the tilt-frame, to $90^{\circ}$ as shown in Fig. 1(e). To change to the other side, the rotateframe has to rotate the $\alpha$-angle to $180^{\circ}$; then, tilt the frame back to $\theta=0^{\circ}$. The size of the bed when the tilt-frame was at $90^{\circ}$ was L5580, H4660, and W4850 mm, as shown in Fig. 2(a). The coordinate of the bed is shown in Fig. 2(b). Note that his report did not include the operation condition for a suitable rotational speed of the tilt-frame which influenced the elephant oscillation and elephant-toframe collision. The speed can be studied by the use of dynamic analysis.

The objective of this paper was the use of computeraided design/computer-aided engineering (CAD/CAE) to illustrate the prospect of virtual motion analysis during the lifting. The CAE application for the analysis was computation mechanism dynamics (CMD). The CMD analyzed the motion during the lifting and determining the suitable rotational speed for the lifting. The simulation was based on the $\theta$-rotation of the tilt-frame of the bed by Chamsa [21]. The rotation of $\alpha$ was not included in this initial study, because it did not contribute the lifting.

a)
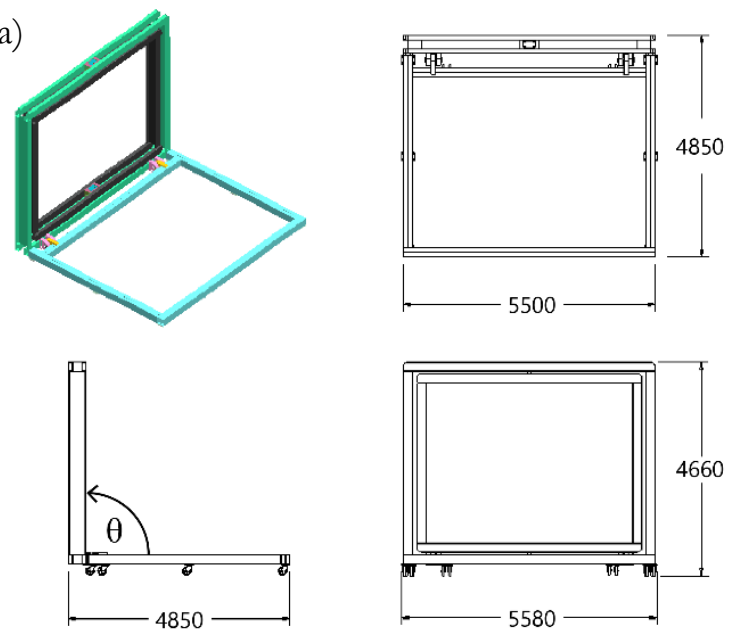

b)
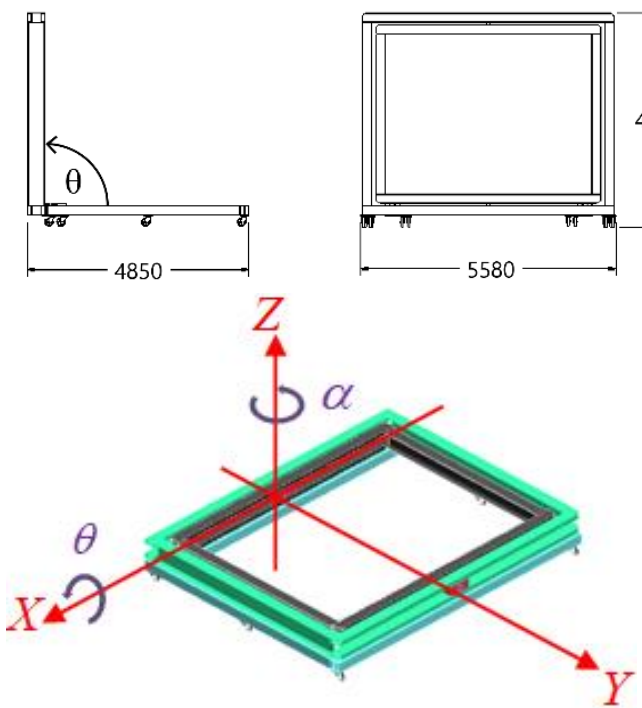

Fig. 2. a) The dimension of Chamsa's elephant bed when the tilt-frame is at $\theta=90^{\circ}$. b) The coordinate of the bed.

\section{Joint Anatomy and Mechanism}

Animal joints, as well as human joints, are connectors that hold ends of two bones and allow them to move relatively with each other. The joints are structures consist of bones and connective tissues such as cartilage, ligament, and tendons [22]. We could find joint information about humans more than animals; however, the joint anatomy of the two was similar. The human and animal joints are neck, shoulder, elbow, wrist, hip, knee, and ankle joint. The simplest joint is a pin joint; examples are knees, elbows, fingers, and toes. The pin joints allow one rotation as the extension and flexion of knees and elbows [23]. A more complicated type of joint is the wrist joint which allows three rotations (flexion-extension, pronation-supination, and radial-ulnar deviation).

The biological joints and bones can be approximated by mechanisms consist of mechanical joints and linkages. Joints allow the combination of motion in translation and/or rotation. The commonly used joint types with their degree-of-freedom or DOF are summarized in Table 1.

\section{Mechanical Modeling Method}

The multi-body dynamics of an elephant being lifted by the tilt-frame was performed by using mechanical computer-aided design (MCAD), the software was PTC's Creo Parametric 4.0, academic edition. The technology of the software is feature-based parametric solid modeling. It was used for creating the frame structure, elephant skeleton (or linkage), and elephant 3D surface model. 
Table 1. Mechanical joints and their degree-of-freedom (DOF).

\begin{tabular}{lcccc}
\hline \multirow{2}{*}{ Joint Type } & \multicolumn{3}{c}{ No. of DOF } & \multirow{2}{*}{ Symbol } \\
\cline { 2 - 5 } & Tran. & Rot. & Total & \\
\hline $\begin{array}{l}\text { Slider } \\
\text { (rigid joint on } \\
\text { slot) }\end{array}$ & 1 & - & 1 & \\
\hline $\begin{array}{l}\text { Pin, hinge } \\
\text { (revolute joint) }\end{array}$ & - & 1 & 1 & \\
\hline $\begin{array}{l}\text { Cylinder } \\
\text { (revolute joint } \\
\text { on slot) }\end{array}$ & 1 & 1 & 2 & 3 \\
\hline $\begin{array}{l}\text { Planar } \\
\text { (revolute joint } \\
\text { on plane) }\end{array}$ & 2 & 1 & 3 & \\
\hline $\begin{array}{l}\text { Ball } \\
\text { (spherical joint) }\end{array}$ & - & 3 & 3 & 工 \\
\hline
\end{tabular}

The created parts were assembled to their corresponding assembly along with the associated mechanism. The assembly and the dynamic analysis were performed by the mechanism dynamics application in the same software. The modeling details of each assembly are as follows.

\subsection{Scaled Experimental Bed (SEB)}

Since no live animals were used in this research; therefore, before we started the full-scale simulation, a 1:16 scaled experimental bed (SEB) was constructed. It was intended for evaluating the correlation between the physical system and the computer model. The SEB was powered by a servo motor on the $\mathrm{x}$-axis. The rotational speed $\omega$ was controllable from 0 to $5 \mathrm{rpm}$; this controlled angle $\theta$ was recorded by an encoder as shown in Fig. 3(a). For this initial study of elephant lifting, a rectangular block of mass $0.917 \mathrm{~kg}$, was used as shown in Fig. 3(b).

The constructed SEB included the tilt-lifting mechanism, mass, and rope (harness). For this initial study, we concerned the motion of the tilt angle $\theta$; as pointed out before, the rotation of $\alpha$ was not included. The motion of points $\mathrm{A}$ and $\mathrm{B}$ was video recording.

\subsection{Frame Mechanism Model (FMM) for Tilt- Lifting}

The solid model of the tilt-frame was created and assembled in the MCAD. The mechanism condition at the rotating x-axis, as indicated in Fig. 2(b), was a pin. The pin allowed motion in one circular DOF; this $\theta$ motion was the input for controlling the rotation from $0^{\circ}$ to $90^{\circ}$ by a required displacement function.

Since the tilt-frame angle $\theta$ was the excitation, we could assume the frame to be rigid and massless. The frame mechanism model (FMM) of the 1:16 tilt-frame was created; and later, the modeling of the actual size would base on this scaled version.
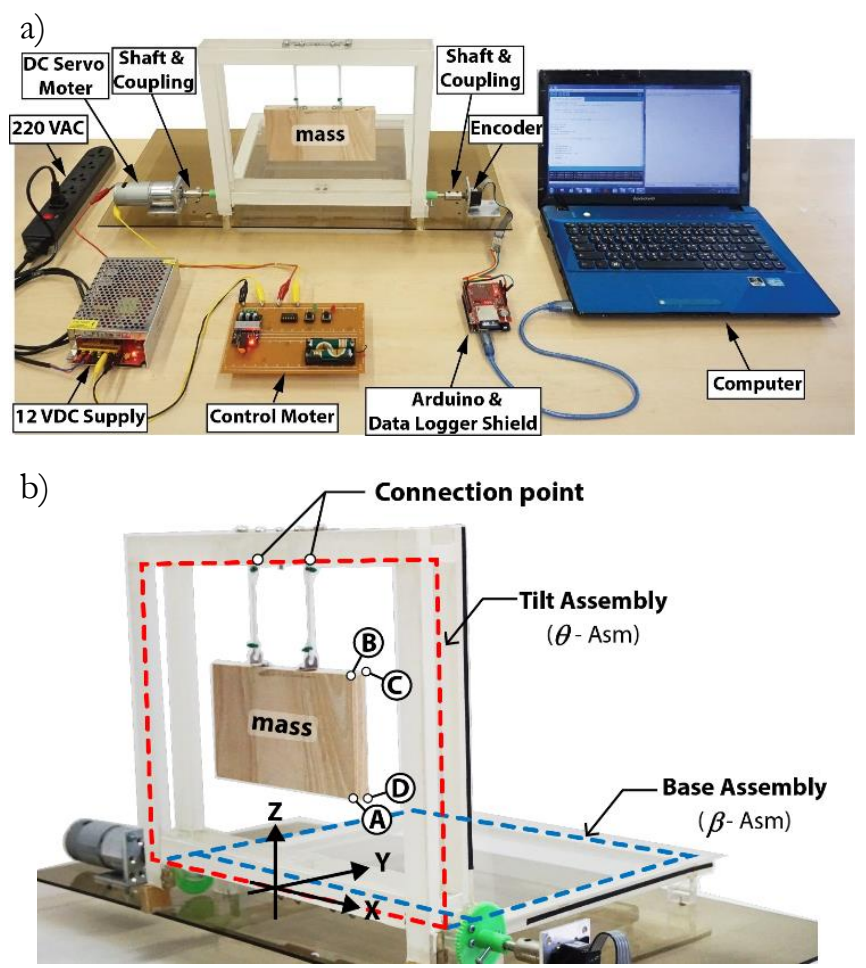

Fig. 3. a) The experimental setup of the 1:16 scaled model for verification of the computation mechanism model. b) The 1:16 model showing the reference coordinates of the assembly at $\theta=90^{\circ}$.

\subsection{Mechanical Harness Model (MHM) and Slide- and-Liftoff Mechanism (SLOM)}

The harness as seen in Fig. 1(a) and Fig. 1(b) served as lifting straps. It is made from bundles of braided ropes. The elephant was wrapped around by the harness; then, its two ends were fastened to the frame.

For simplicity of analysis, we proposed this flexible harness by an equivalent straight linkage model. The mechanical harness model (MHM) is shown in Fig. 4(a). The dimension is the 1:16 model, and C1 to C6 are coordinates necessary for defining the joints. The diagram shows the MHM consists of three linkages. The first linkage is $\mathrm{C} 2$ to $\mathrm{C} 3$; the pin joint is used at $\mathrm{C} 2$. The second (C3 to C4) is a cylindrical joint. The third (C5 and C6) has a pin joint at $\mathrm{C} 5$, and a ball joint at $\mathrm{C} 6$. The coordinate $\mathrm{C} 1$ is at the top beam of the tilt-frame, and C6 is at the mass. Therefore, there are 4 joints for the mechanism of FMM and MHM (two pins, one cylindrical joint, and one ball joint) for a total of 7 DOFs.

The elastic and viscous properties, of the first linkage, were assumed by spring and damper. The diagram of Fig. 4(b) shows the upper end (C2) of the harness connected to $\mathrm{C} 1$ at the top frame of FMM; while, the lower end (C6) to the lifting mass.

Before lifting, the mass must be on the ground surface. It would slide and kept contact on the surface; after a while, the upper corner (point C) lifted off, whiles the lower corner (point D) remain touching and sliding. Finally, the lower corners lifted off. This slide-and-liftoff 


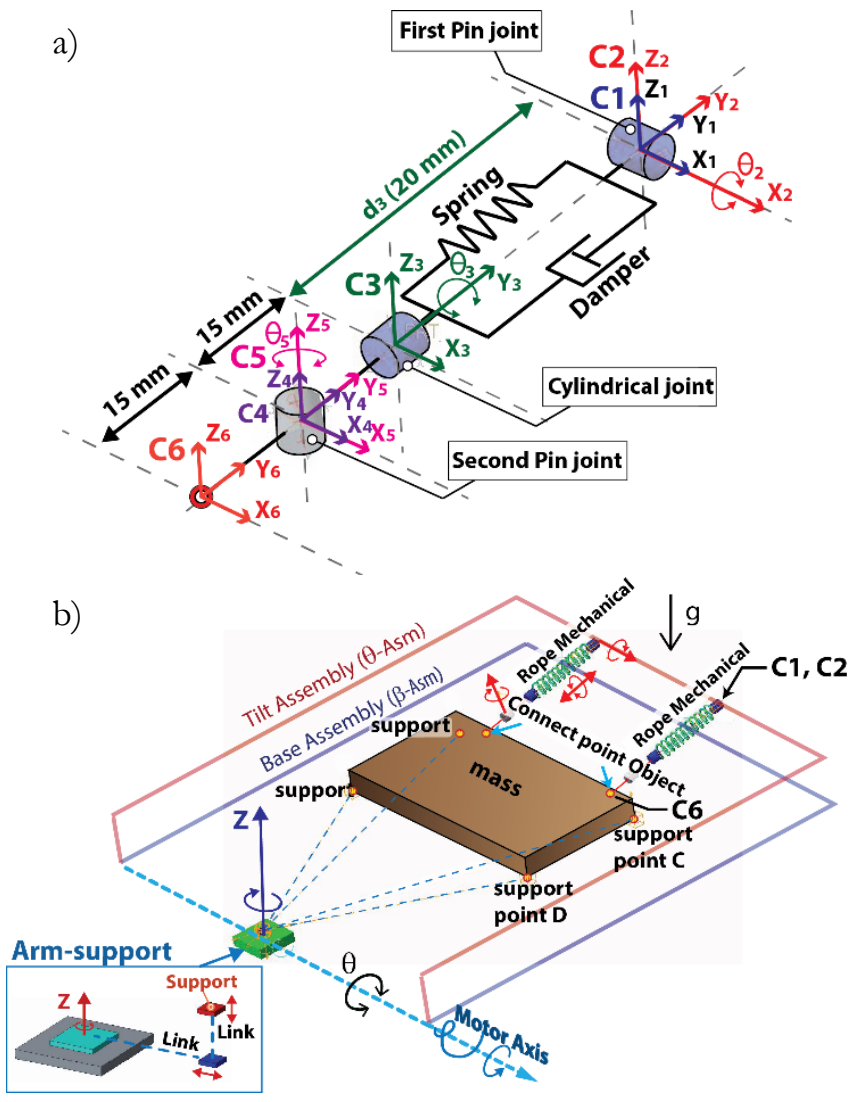

Fig. 4. a) Mechanism model of the harness for the elephant lifting. b) The assembly of harnesses to the tiltframe model (or FMM) and the mass when $\theta=0^{\circ}$.

mechanism (SLOM) was model by using one planar and one slider as shown, by the inserted view, in Fig. 4(b). The surface-contact-mechanism condition is indicated by "support"; there are four supports in Fig. 4(b). For simplicity, both static and kinetic frictions were not assigned for the sliding.

The completed computer model of the SEB, in Fig. 4(b), consists of FMM, MHM, SLOM, and a mass; which, we called this model as the computer-SEB model or C-SEBM.

\subsection{Elephant Mechanism Model (EMM)}

The elephant skeleton was first evaluated for the significant motion of body segments. In Fig. 5(a), by using the lateral view [13], the polyline of bone structure is drawn on the figure. The cervical, shoulder, thoracic, lumbar, and ilium were observed to have no translation and rotation; or no spinal bending. Hence, we could combine them as one main structure for supporting body segments.

It is customary to call limbs of 4-leg animals as forelimbs or front legs (contains upper arm and forearm, same for left and right sides), and the hind-limbs or back legs are thigh and shank.

The head and limbs had noticeable displacement related to their connected segments; these enable us to approximate them by straight lines as shown in Fig. 5(b). a)

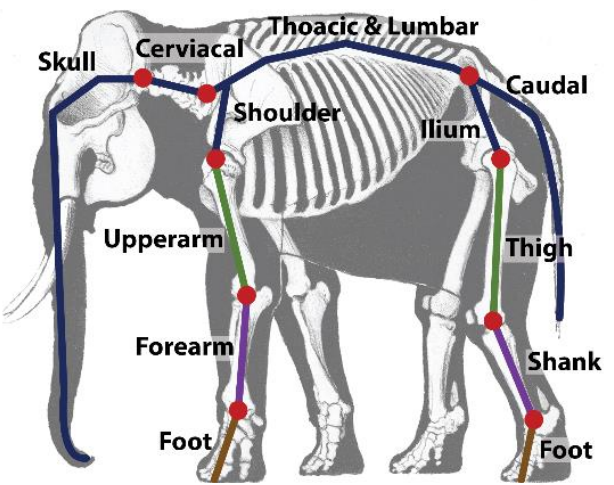

b)

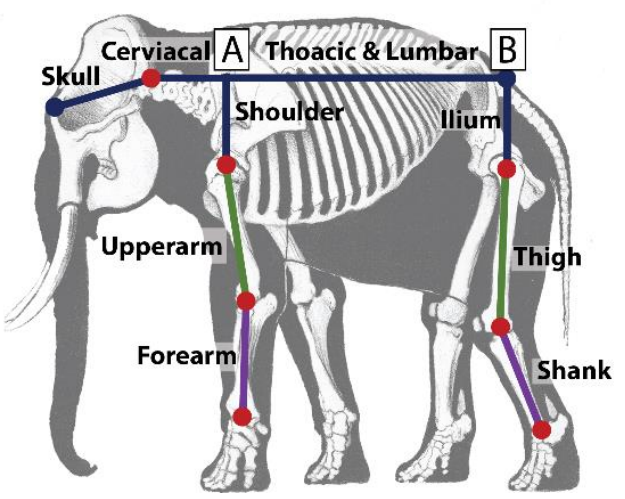

c)

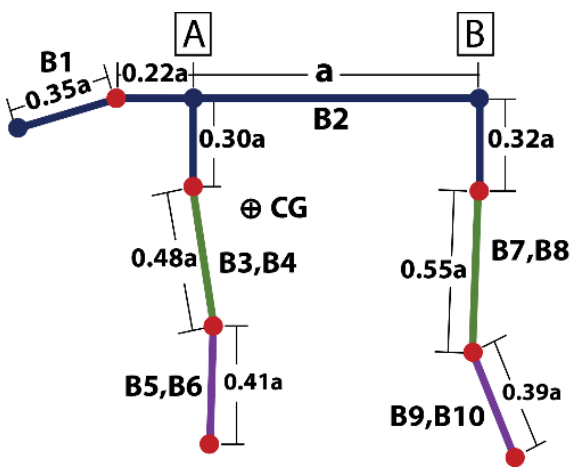

Fig. 5. a) Lateral view showing the elephant skeleton superimposes by the linkages approximation of bones and joints. b) Straight lines simplification of the bones. c) Bones in (b) showing their lengths as a factor of the length "a" (between points A and B).

The straight-line skeleton approximation, of each bone in Fig. 5(c), has the dimension according to the length factor " $a$ " (the length between points A and B). This length factor allowed us to change the elephant dimension to any size.

The elephant mechanism model (EMM) was divided into 10 body segments. The head, skull, trunk, tusks, and ears were combined and represented by an ideal linear bone (B1). Similarly, the linear bone was assumed for the body (B2), and limbs (B3 to B10).

The rotation of ankle joints, at the four feet, showed to be small; hence, each front foot was combined with the segment of the forearm, similarly for the shanks.

All joints consist of 6 DOFs; it has three translations in $\mathrm{x}, \mathrm{y}$, and $\mathrm{z}$ of the Cartesian coordinate system, and three rotations around the three axes. The joint assigned to the elephant skeleton is shown in Fig. 6(a). The major bones 

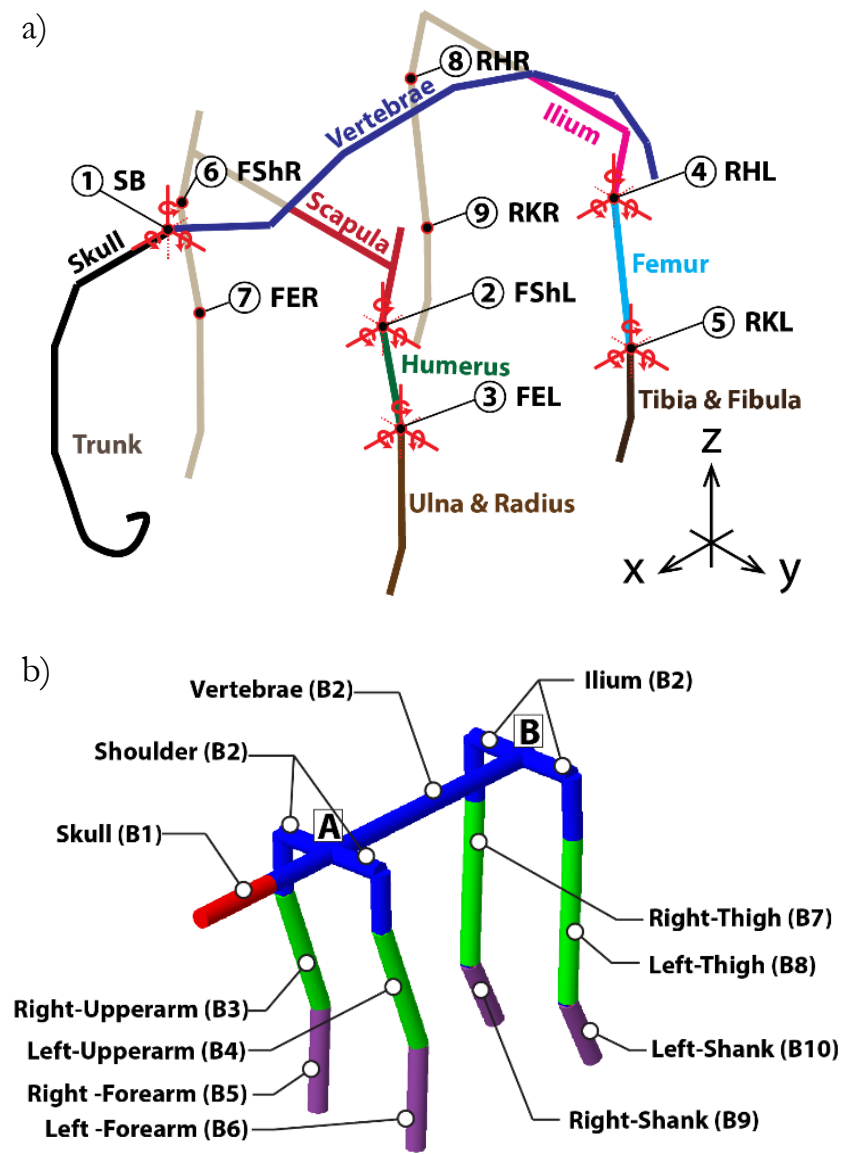

c)

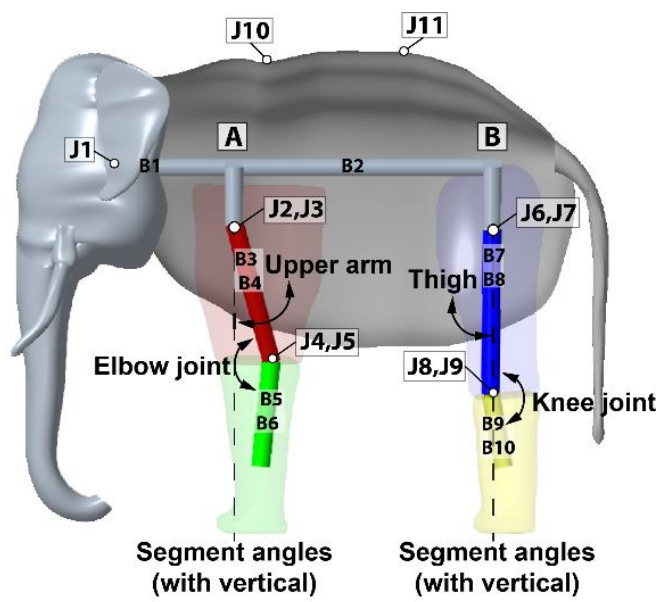

Fig. 6. a) Simplified 3-D skeleton of the bones and joints. b) Bone assignment as mechanical linkages. c) Linkage model inside the elephant surface model showing the joint angles and their range-of-motion.

in the skeleton were converted to mechanical linkages. The linear geometry linkages approximation of the skeleton in Fig. 6(a) is shown in Fig. 6(b). The total of 10 bones was modeled as linkages. Examples of linkage and bone assignments, in Fig. 6(b), are B1 for the skull, B2 for the combination of shoulder, vertebrae, and ilium, B3 for the right upper arm, and so on.

For realistic shapes, surface models of elephant segments were created by using MCAD. Each nondeformable surface model was assigned to their corresponding linkages as shown in Fig. 6(c). The envelope size of the elephant was L3464, H2798, and W1450 mm.

The joints connect the bones, Fig. 6(c), are as follows: joint J1 between bones B1 and B2, J2 between B2 and B3 of the right upper arm, J3 between B2 and B4 of the left upper arm; similarly for the remaining limbs. Using this configuration, the EMM had a total of 9 joints with 54 DOFs.

The joint head (J1) was observed to have two rotational-DOFs. The limb had little sideways motion, and its extension and flexion were assumed to remain on the same para-sagittal plane. Under this assumption, we assumed the limb joint as a pin; and the DOF of the elephant reduced to 10 .

Joints J10 and J11 were for harness connections; each was a ball joint with 3 DOFs. During the lifting, additions of 6 DOFs at the elephant's center-of-gravity (CG) were the displacement in $\mathrm{x}, \mathrm{y}$, and $\mathrm{z}$; and orientation: pitch, yaw, and roll.

Each relative angular displacement of the joint angle between two linkages, in Fig. 6(c), was limited by their range-of-motion (ROM). The ROM of each joint is shown in Table 2; the mid-stance is the default angle in standing posture. Torsion spring and damping constants could be assigned at each joint for simulating the muscle stiffness that regulated the default angular position.

Table 2. Minimum, mid-stance, maximum, and range-ofmotion of the elephant limb joints.

\begin{tabular}{|c|c|c|c|c|}
\hline \multirow[b]{2}{*}{ Segment } & \multicolumn{4}{|c|}{ Joint angle (deg.) } \\
\hline & Min. & $\begin{array}{l}\text { Mid- } \\
\text { stance }\end{array}$ & Max. & $\begin{array}{c}\text { Range-of- } \\
\text { motion }\end{array}$ \\
\hline $\begin{array}{l}\text { Upper arm } \\
(\mathrm{J} 2, \mathrm{~J} 3)\end{array}$ & -41 & -19 & 1 & 42 \\
\hline $\begin{array}{c}\text { Elbow joint } \\
(\mathrm{J} 4, \mathrm{~J} 5)\end{array}$ & 122 & 157 & 157 & 35 \\
\hline $\begin{array}{l}\text { Thigh } \\
(J 6, J 7)\end{array}$ & -2 & 4 & 24 & 26 \\
\hline $\begin{array}{c}\text { Knee joint } \\
(J 8, J 9)\end{array}$ & 122 & 152 & 163 & 41 \\
\hline
\end{tabular}

\subsection{Elephant Mechanism Dynamic Model (EMDM)}

The mechanical skeleton-and-joint model of the EMM described in Section 3.4 was massless and was not possible for the dynamic analysis. The mass assigned to each linkage was assumed by simple solid geometry which allowed assigning the mass by the density. The CG of each mass segment was approximated on the corresponding linkage. The CG approximation was done by using elephant anatomy and research data by Evans [24]. Note that the masses included the bones and the corresponding internal organs.

For an elephant of mass $2743 \mathrm{~kg}$, the mass of the 10 body segments is shown along with their percentages in Fig. 7(a). The reason, for selecting the mass of $2743 \mathrm{~kg}$, 

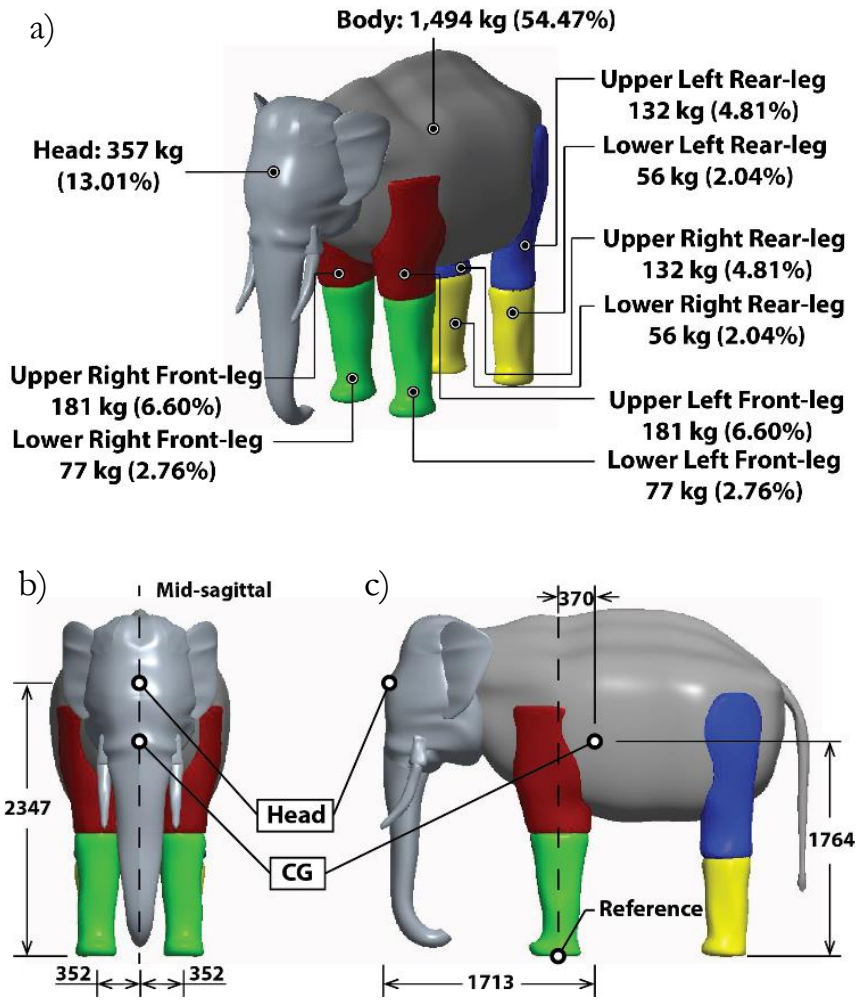

Fig. 7. a) The mass assignment at each body segment. b) Anterior view showing the model center-of-gravity (CG) and the head measuring point on the mid-sagittal plane. c) The CG and head in the lateral view, and the reference coordinate at the ground and front feet.

was it was the average elephant mass [24]. The EMM with its segment masses was called the elephant mechanism dynamic model (EMDM). The obtained EMDM had the CG location as shown in the frontal view and lateral view of Fig. 7(b) and Fig. 7(c), respectively. The location of the CG is on the mid-sagittal plane; and a plane, parallel to the frontal plane, which passes through the front axis of vertical legs. The vertical leg axis was a line passing through the center of the front sole foot. The indicated points, CG and head, in the figures are locations to be evaluated for the motion responses during tilt-lifting. Note that, it is possible to assign an active muscle force by using "motor force function" at the joint; also, the joint friction can be specified.

\section{Simulation Result}

\subsection{Simulation of the Scale Model}

The model verification was performed by using the 1:16 scaled structure, or the SEB described in Section 3.1. The lifting time used for observing the motion was 4.36 seconds or the frame rotated with the rotational speed $\omega$ of $3.44 \mathrm{rpm}$. The lifting time is the transition time, which controls the tilt-frame of $\mathrm{SEB}$, to rotate from $0^{\circ}$ to $90^{\circ}$. To minimize the input error of the CMD simulation, the time records of the angular displacement during the lifting time of SEB was used as the externally applied angular displacement at $\theta$-coordinate of the computer-SEB model (C-SEBM).
The gravity of $9.81 \mathrm{~m} / \mathrm{sec}^{2}$ was assigned in the negative z-direction of the C-SEBM in Fig. 4(b). The lifting mass was $0.917 \mathrm{~kg}$; the stiffness and damping constant for the harness were $100 \times 10^{3} \mathrm{~kg} / \mathrm{sec}^{2}$ and $10 \times 10^{3} \mathrm{~kg} / \mathrm{sec}$, respectively.

The displacement comparison between the video recording of the experimental SEB and C-SEBM is shown in Fig. 8. The side-by-side images compare the yz-plane view of the motion of points A and B (see Fig. 3(b)) at times $0,1,1.2,2,3$, and 4.05 seconds. The lengths of the horizontal and vertical arrows indicate the displacement of point $\mathrm{A}$. We could observe that point $\mathrm{D}$ was sliding and contacting on the ground up to 1.7 seconds. After this time, point $\mathrm{D}$ was lifted above the ground, and the mass swung to the right (as shown at 2 seconds); the images illustrate the resemblance between the two.

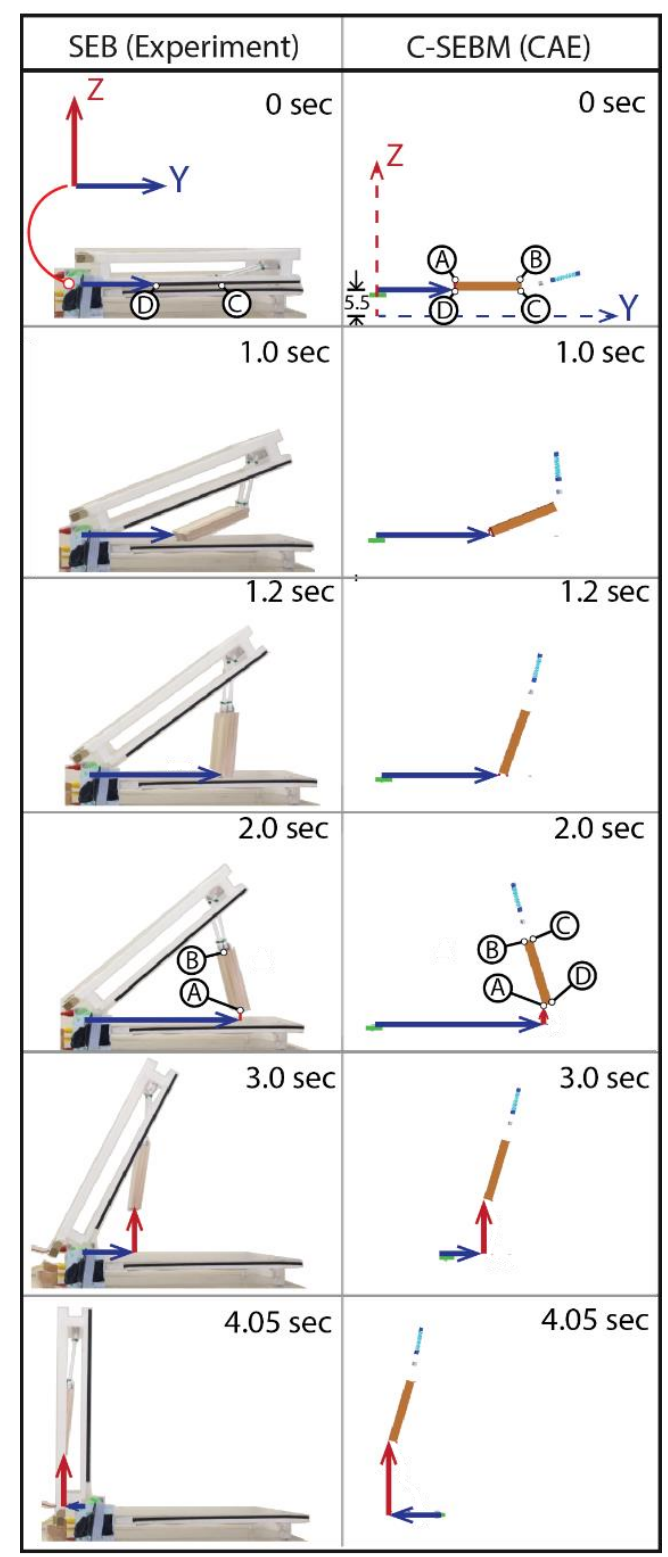

Fig. 8. Comparison of the video of SEB and C-SEBM at times: $0,1,1.2,2,3$, and $4.05 \mathrm{sec}$. The blue (horizontal) and red (vertical) vectors correspond to the displacement in $y$ and $z$ directions. The lifting time from $0^{\circ}$ to $90^{\circ}$ is $4.05 \mathrm{sec}$. 
The displacement responses against time, of points $\mathrm{A}$ and B, are shown in Fig. 9 (upper and lower, respectively). The $y$ and $z$ responses are in the left and right columns, respectively. The smooth curves belong to the simulation C-SEBM, and the dots are from the experiment. Comparing these results, the C-SEBM curves are closely following the dots of the experiment. Note that the zeroreference of the $z$-axis was $5.5 \mathrm{~mm}$ above the ground; which was the initial z-position of points A and B.

\subsection{Elephant Dynamic during Tilt-Lifting}

The full-size model for simulating the elephant lifting was the assembly of the FMM, MHM, SLOM, and EMDM; which we referred to the elephant dynamic during tilt-lifting model (EDTM). The assembly dimension of the elephant (EMDM) and harness (MHM) referenced with the frame (FMM) is shown in Fig. 10(a) and Fig. 10(b). The frontal image in Fig. 10(a) shows the initial position of the elephant when it is laying on its left side; and the four support points (SLOM) contact on the ground. Fig. 10(b) illustrates the lateral view and the four support locations. The frame structure of the bed was assumed to be massless and rigid, as we used in the CSEBM.

The two harnesses were assembled at joins of the FMM and EMDM. The stiffness and damping of the harness were modified to a larger value according to the mass to be lifted. The selected value of the stiffness gave the static deflection when $\theta=90^{\circ}$, of $2.68 \mathrm{~mm}$. The elephant joints were assumed to have the spring and damping constants of $10 \times 10^{6} \mathrm{~kg} / \mathrm{sec}^{2}$ and $10 \times 10^{4} \mathrm{~kg} / \mathrm{sec}$, respectively. The damping as was from our observation that the limbs had small motion.

The motion responses of the elephant were calculated at CG and head; while any points on the elephant model were possible to observe by using the CMD.

The front and top views from the simulated result at $\theta=0^{\circ}, 45^{\circ}$, and $90^{\circ}$ are shown in Fig. 10(c). The EDTM motion responses are shown in Fig. 11. The graphs are the displacement, velocity, and acceleration responses in $\mathrm{x}$, $y, z$, and their magnitude. The three lifting speeds $\omega$ of 1 , 0.428 , and $0.272 \mathrm{rpm}$ corresponding to the lifting times, from $\theta=0^{\circ}$ to $90^{\circ}$, of 20,40 , and 60 seconds, respectively. Note that the horizontal axis shared the angular displacement with times of each speed. For example at the time of $\theta=30^{\circ}$; when $\omega=1,0.428$, and $0.272 \mathrm{rpm}$ are $5,11.673$, and 18.349 seconds, respectively.

An example of the responses in the y-direction, at CG and head, including the time greater than the lifting time, is shown in Fig. 12. This figure shows the responses from 0 to 100 seconds when the lifting speed $\omega$ is $1 \mathrm{rpm}$ (or the lifting time of 20 seconds); that is, we observe the responses for another 80 seconds while the tilt-frame remains at $90^{\circ}$. The graphs show the responses are slowly reached their steady-state values.

It was worth mentioning that each EDTM simulation in Fig. 12 took the computer processing time up to 5 hours
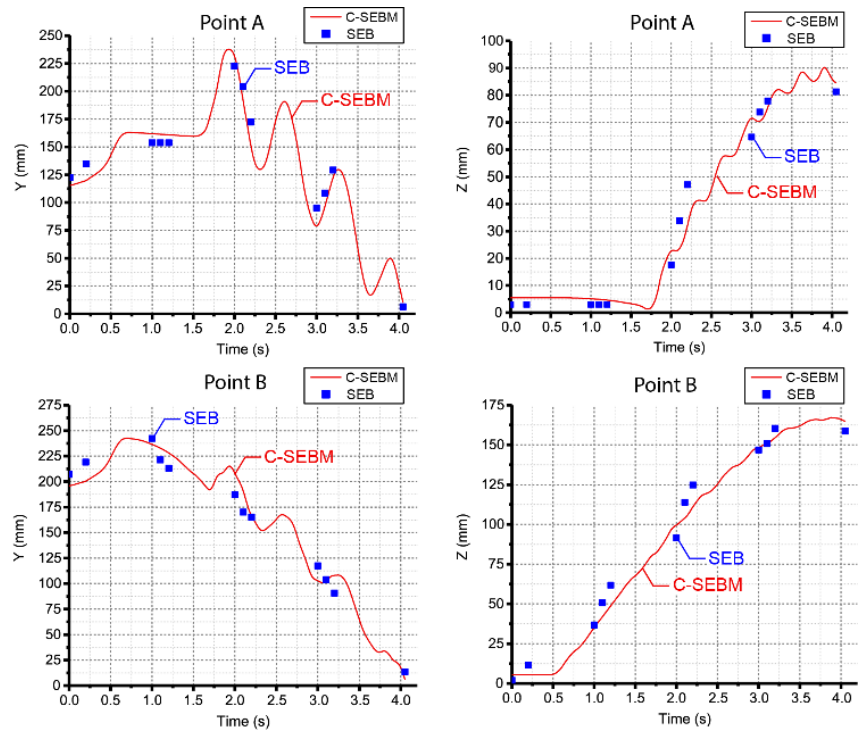

Fig. 9. Comparing the displacement of points $A$ and $B$ in $y$ and $z$ directions of SEB and C-SEBM.

a)
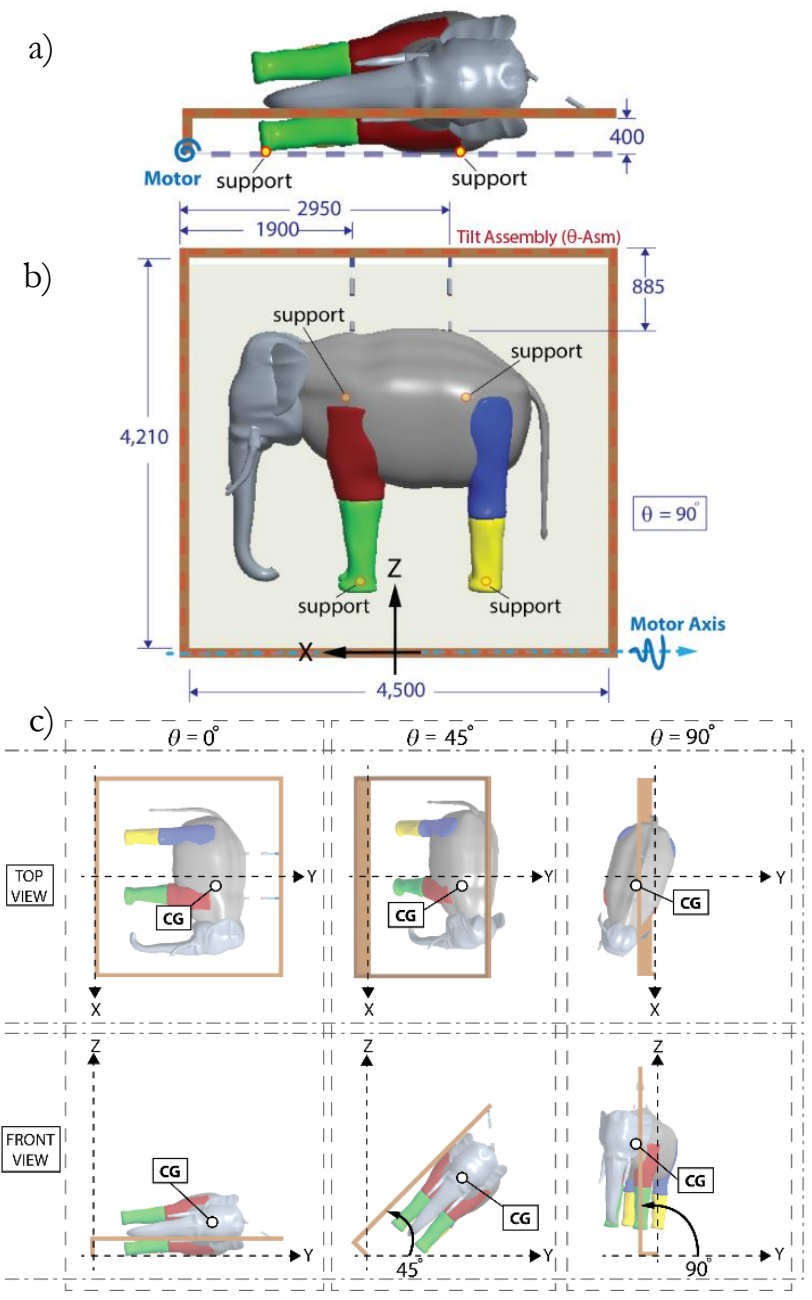

Fig. 10. The assembly dimension: a) front view of EDTM when it lays on the left side, and b) lateral view when $\theta=$ $90^{\circ}$. c) Examples of the elephant motion (top and front views) during the lifting at $\theta=0^{\circ}, 45^{\circ}$, and $90^{\circ}$; this illustration shows the center-of-gravity (CG) of the elephant with respect to the indicated reference coordinate. 

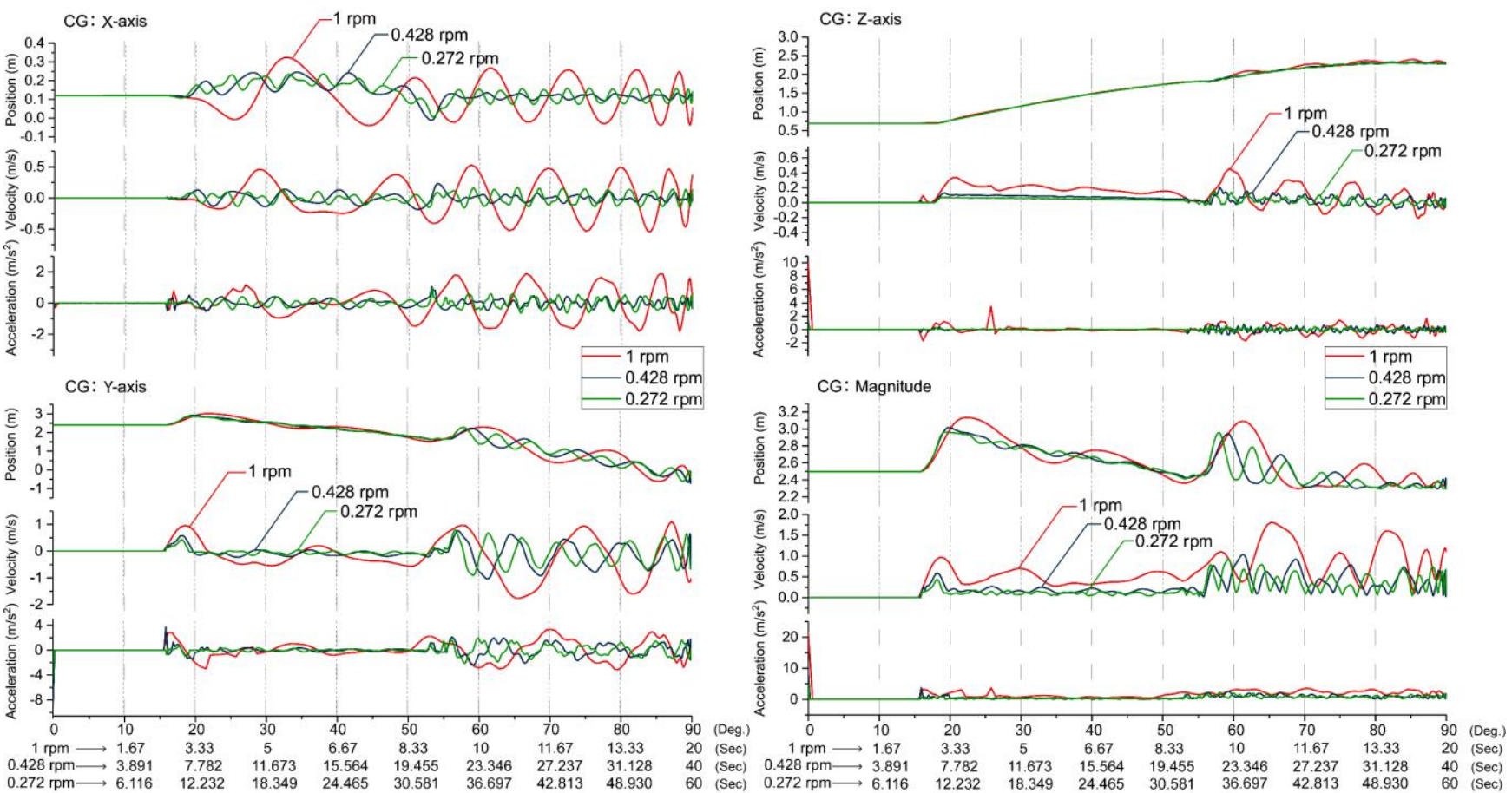

Fig. 11. The displacement, velocity, and acceleration responses of the CG at $x, y, z$, and magnitude. The horizontal axes shares the angular displacement $\left(\theta=0^{\circ}\right.$ to $\left.90^{\circ}\right)$ and the corresponding lifting times: 0 to 20,0 to 40 , and 0 to 60 seconds when $\omega=1,0.428$, and $0.272 \mathrm{rpm}$, respectively.
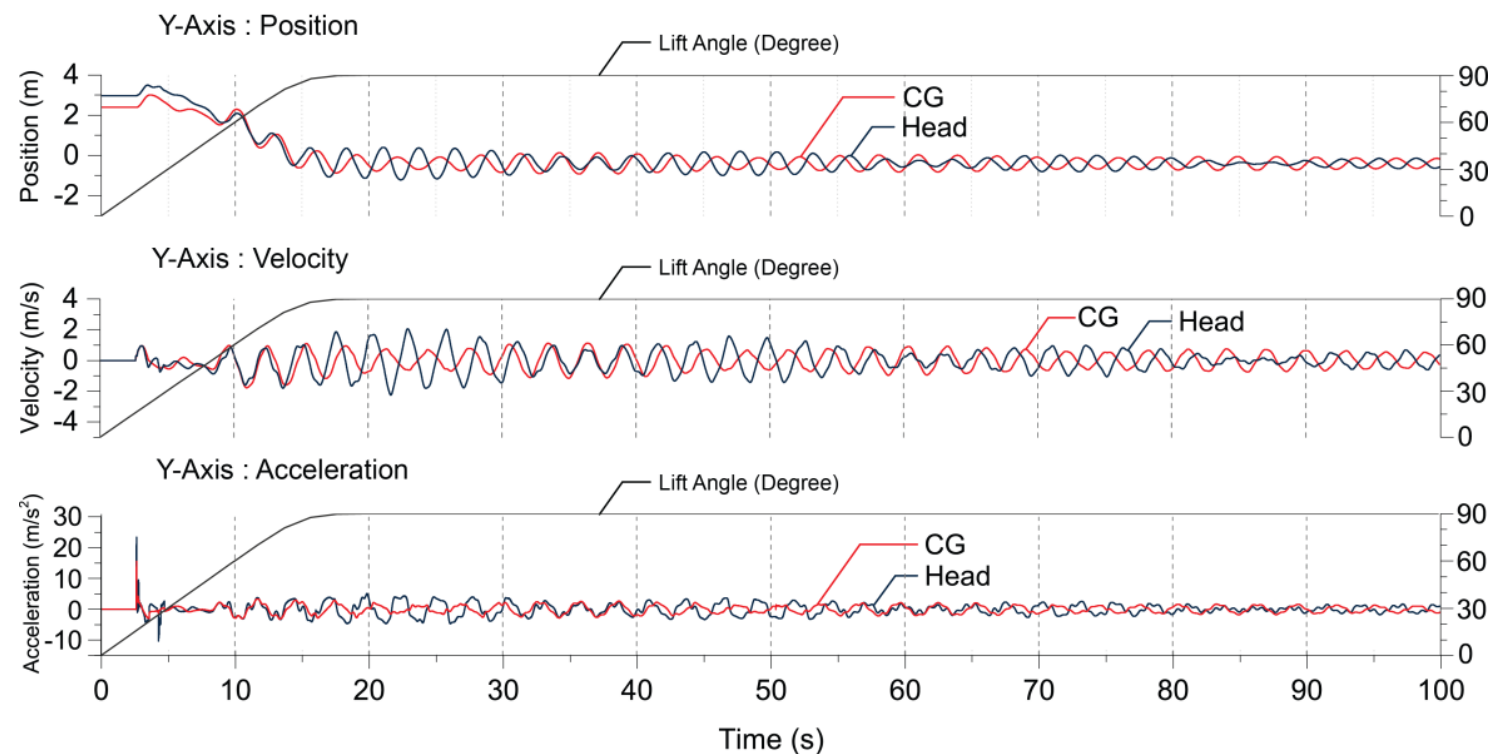

Fig. 12. The responses of CG and head in the y-direction from 0 to 100 seconds; the lifting time is 20 seconds (or $\omega$ $=1 \mathrm{rpm})$.

and 30 minutes. The computer, for processing the $\mathrm{CMD}$, had $4 \mathrm{GHz}$ Intel Core i7-6700K CPU, RAM of $32 \mathrm{~GB}$ and 2 GB graphic memory. It was evident that the more the number of DOFs, the longer the computer processing time.

The radial plot in Fig. 13 summarizes the maximum value of displacement, velocity, and acceleration in $\mathrm{x}, \mathrm{y}, \mathrm{z}$, and magnitude, from the response similar to Fig. 12. The horizontal axis represents the values on xy-plane; the left side represents the $\mathrm{x}$-direction and the right for $\mathrm{y}$ direction. The upper vertical axis represents the $z$-axis, or the height above the ground; while, the lower axis is the magnitude.

According to the radial graph of Fig. 13, the maximum displacements at CG and head show no significant difference in $\mathrm{x}, \mathrm{y}, \mathrm{z}$, and magnitude for the three speeds. The highest velocity is at y-direction; also, velocities of the fastest lifting speed $(1 \mathrm{rpm})$ are faster than the two slower speeds. The head had the maximum acceleration in the $\mathrm{z}$ axis. Acceleration at the head is higher than CG due to the head has longer distance from the neutral axis. The accelerations indicated the faster the speed, the higher the acceleration. 

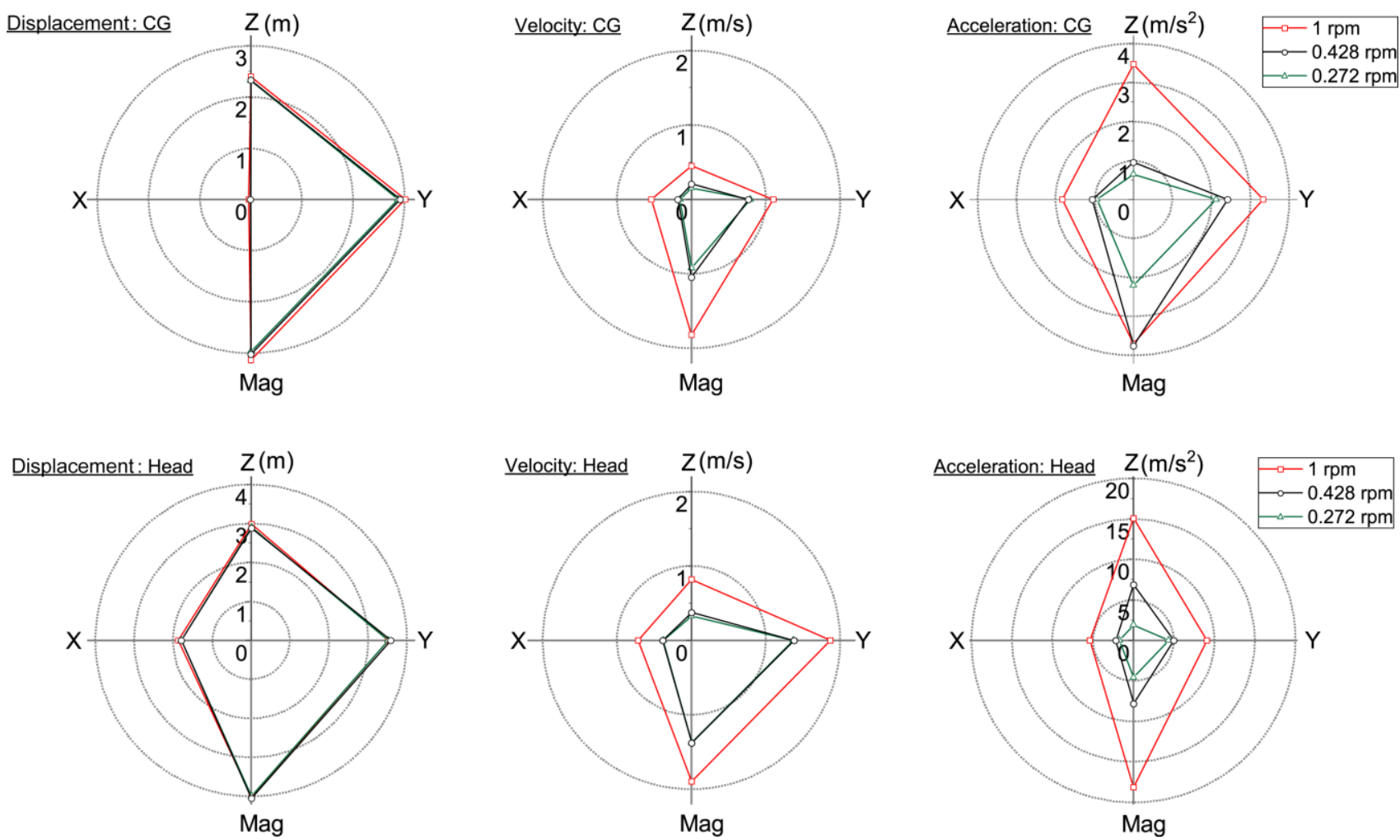

Fig. 13. The radial plot of the maximum displacement, velocity, and acceleration in $x, y, z$, and magnitude at CG and head of the elephant.

\section{Conclusions}

This paper presented a dynamic model for simulating elephant motion under tilt-lifting for the computation mechanism dynamic (CMD) analysis. The developed models were mechanical harness model (MHM), slideand-liftoff mechanism (SLOM), elephant mechanism model (EMM), and elephant mechanism dynamic model (EMDM). The multi-body dynamic model was the assembly of MHM, SLOM, and EMDM to the frame mechanism model (FMM); we called it an elephant dynamic during tilt-lifting model (EDTM). Due to the limited facilities, time, cost, and the ethics of animal experimentation, no live elephant was used; but, we constructed a 1:16 scaled experimental bed (SEB) and a computer-SEB model (C-SEBM) for the initial verification study. The C-SEBM was the scaled-down of the EDTM but using a rigid block instead of the EMDM. The average deviation between them was $5.38 \%$. Then we progressed to our objective of using the actual size EDTM for the CMD analysis. The elephant of mass 2743 $\mathrm{kg}$ with the envelope size of L3464, H2798, and W1450 $\mathrm{mm}$ was select for the simulation. Unlike the study of locomotion where the motions were voluntary controlled by muscles, our interest was an external activated motion (the lifting) that caused the whole elephant body movement. The result simulation indicated the slow lifting time reduced the maximum acceleration magnitude at the elephant head which expected to reduce the elephant's fear of lifting. The displacement responses gave us the idea of the safety clearance of the head and tail in hitting the frame. Our developed EDTM could analysis the working condition of the bed and provided initial useful information for veterinaries for evaluating the possibility of the usages, and engineers for the better design. The advantages of the proposed EDTM are the elimination in time, effort, development cost, resources, and facilities for the testing; and allow us to perform the study anywhere and anytime. With a better computation system, we hoped to develop a more accurate model in the future. Lastly, this practice would pave the way for the future development of better computer modeling and testing simulation on animals.

\section{Acknowledgments}

Our special thanks to Royal Veterinarian M. L. Phiphatanachatr Diskul, veterinarian Taweepoke Angkavanich, and veterinarians from the National Elephant Institute, Lampang, Thailand for the elephant information they kindly provided.

This study was supported by the Graduate Engineering Student Scholarship from the Faculty of Engineering, Kasetsart University, Bangkok.

This work was done and used the CAD and FEA programs in the Mechanical and Product Design Research Laboratory (MPDRL) at the Department of Mechanical Engineering, Faculty of Engineering, Kasetsart University. 


\section{Acronyms}

$\begin{array}{ll}\text { CAD } & \text { computer-aided design } \\ \text { CAE } & \begin{array}{l}\text { computer-aided engineering } \\ \text { CG }\end{array} \\ \text { center-of-gravity } \\ \text { CMD } & \text { computation mechanism dynamic } \\ \text { COM } & \text { center-of-mass } \\ \text { C-SEBM } & \text { computer-SEB model } \\ \text { DOF } & \text { degree-of-freedom } \\ \text { EDTM } & \text { elephant dynamic during tilt-lifting model } \\ \text { EMDM } & \text { elephant mechanism dynamic model } \\ \text { EMM } & \text { elephant mechanism model } \\ \text { FMM } & \text { frame mechanism model } \\ \text { MCAD } & \text { mechanical computer-aided design } \\ \text { MHM } & \text { mechanical harness model } \\ \text { ROM } & \text { range-of-motion } \\ \text { SEB } & \text { scaled experimental bed } \\ \text { SLOM } & \text { slide-and-liftoff mechanism }\end{array}$

\section{References}

[1] M. Chen and J. F. Liu, "Virtual simulation of production line for ergonomics evaluation," Advances in Manufacturing, vol. 2, no. 1, pp. 48-53, Mar. 2014.

[2] L. Zhao, Y. Zhang, X. Wu, and J. Yan. "Virtual assembly simulation and ergonomics analysis for the industrial manipulator based on DELMIA, " in Proceedings of the 6th International Asia Conference on Industrial Engineering and Management Innovation, 2016, pp. 527-538.

[3] A. J. Subic and S. J. Haake, The Engineering of Sport; Research, Development and Innovation. London: Blackwell Science, 2000.

[4] K. Zimmermann, I. Zeidis, and C. Behn, Mechanics of Terrestrial Locomotion. Springer-Verlag Berlin Heidelberg, 2009.

[5] J. Li, J. Wang, S. X. Yang, K. Zhou, and H. Tang, "Gait planning and stability control of a quadruped robot," Computational Intelligence and Neuroscience, vol. 2016, May. 2016, Article ID 9853070, doi: 10.1155/2016/9853070.

[6] M. Öztürk, "Design of SMA base actuators used in robotics," in Proceedings of the 16 th International Conference on Climbing and Walking Robots and the Support Technologies for Mobile Machines, Jul. 2013, pp. 693-700.

[7] K. Narioka, A. Rosendo, A. Sproewitz, and K. Hosoda. "Development of a minimalistic pneumatic quadruped robot for fast locomotion," in IEEE International Conference on Robotics and Biomimetics (ROBIO), Guangzhou, China, 2012.

[8] R. E. Ritzmann, R. D. Quinn, and M. S. Fischer, "Convergent evolution and locomotion through complex terrain by insects, vertebrates and robots," Arthropod Structure and Development, vol. 33, pp. 361379, Apr. 2004.

[9] T. Landgraf, D. Bierbach, H. Nguyen, N. Muggelberg, P. Romanczuk, and J. Krause, "RoboFish: Increased acceptance of interactive robotic fish with realistic eyes and natural motion patterns by live Trinidadian guppies," BioinspirBiomim, vol. 11, no. 1, Jan 12.

[10] V. C. Mow and W. M. Lai, "Mechanics of animal joints," Annual Review of Fluid Mechanics, vol. 11, pp. 247-288, 1979.

[11] J. R. Hutchinson, D. Schwerda, D. J. Famini, R. H. I. Dale, M. S. Fischer, and K. Rodger, "The locomotor kinematics of Asian and African elephants: Changes with speed and size" The Journal of Experimental Biology, vol. 209, pp. 3812-3827, 2006.

[12] J. J. Genin, P. A. Willems, G. A. Cavagna, R. Lair, and N. C. Heglund, "Biomechanics of locomotion in Asian elephants," The Journal of Experimental Biology, vol. 213, no. 5, pp. 694-706, Mar. 2010.

[13] L. Ren, M. Butler, C. Miller, H. Paxton, D. Schwerda, M. S. Fischer, and J. R. Hutchinson, "The movements of limb segments and joints during locomotion in African and Asian elephants," The Journal of Experimental Biology, vol. 211, no. 17, pp. 2735-51, Sep. 2008.

[14] L. Maes and A. Abourachid, "Gait transitions and modular organization of mammal locomotion," The Journal of Experimental Biology, vol. 216, pp. 2257-65, Jun. 2013.

[15] M. Tefera, "Kinematics and comparative anatomy of some limb bones of the African elephant (Loxodonta Africana) and large domestic animals," Journal of Veterinary Anatomy, vol. 5, no. 2, pp. 15-31, 2012.

[16] D. W. Macdonald, Ed., The Encyclopedia of Mammals. Oxford University Press, 2006.

[17] E. Fuller, Elephant. Princeton University Press, 2019.

[18] D. Yarri, The Ethics of Animal Experimentation. Oxford University Press, 2005.

[19] Mechanical Vibration and Shock-Evaluation of Human Exposure to Whole Body Vibration, International Organization for Standardization, ISO 2631, 2004.

[20] W. Du, K. S. Goh, and T. C. Pan, "Methodology for estimating human perception to tremors in high-rise buildings," Journal of Seismology, vol. 21, no. 4, pp. 667682, Jul. 2017.

[21] P. Chamsa, "Design and analysis structure and mechanism of elephant beds for bedsore remedy operation," M.E. thesis, Kasetsart University, Bangkok, Thailand, 2017.

[22] D. Downson and V. Wright, Eds., An Introduction to the Biomechanics of Joints and Joint Replacement. London: Mechanical Engineering Publications Ltd., 1981.

[23] J. Hamill and K. M. Knutzen, Biomechanical Basic of Human Movement. Baltimore: Williams \& Wilkins, 1995.

[24] G. H. Evans, "Elephants and their diseases," in $A$ Treatise on Elephants, 1st ed. Rangoon, Burma, 1910, ch. 1, pp. 4-8. 


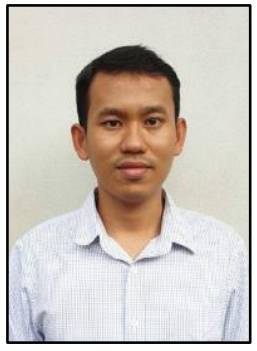

Komsam Mianpet was born in Bangkok, Thailand in 1990. He received the B.Eng. degree in electrical-mechanical manufacturing engineering from Kasetsart University, Bangkok, Thailand, in 2015. Currently, he is pursuing a master degree in mechanical engineering at Kasetsart University.

From 2014 to 2015, he was a teaching assistant in Instrument \& Control Systems Laboratory. In 2016 he participated in the developmen to fan automated orchid plant nurseries for an orchids farm. From 2016 to 2018, he was a laboratory assistant for subjects in computer-aided design and computer-aided engineering at CAD/CAM/CAE Laboratory, Kasetsart University.

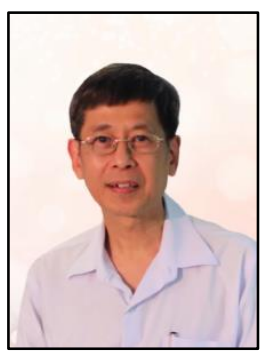

Satjarthip Thusneyapan was born in Bangkok, Thailand. He received the B.S. and M.S. degrees in electrical engineering, and an M.S. degree in mechanical engineering from Washington University, St. Louis, MO, in May 1982, Aug 1982, and 1986, respectively.

Since 1988 he has been a member of the faculty of the Department of Mechanical Engineering, Kasetsart University. His teaching and research interests include control systems, vibrations, biomechanics, CNC technology, design-and-manufacturing using CAD/CAM/CAE, and finite element analysis. In 1991 he was a driven member for the establishment of the Research and Development Institute of Industrial Production Technology, where he administrated until 2000. In 1998 he was a creation member for the novel Electrical-Mechanical Manufacturing Engineering program, his responsibility was course curriculum and description; since then, he has been teaching and consulting for the program. In 2002 he formed Mechanical and Product Design Research Laboratory (MPDRL) and actively researching in this laboratory.

Associate Professor Thusneyapan received the Excellent Award in Engineering Textbook Award from the Faculty of Engineering, Kasetsart University in 2018; his book was "An Introduction to Automatic Control Systems". 